Article

\title{
The socio-demographic factors correlated with financial toxicity among patients with breast cancer in Indonesia
}

\author{
Maelani Susilowati, ${ }^{1}$ Yati Afiyanti² \\ ${ }^{1}$ Faculty of Nursing, Universitas Indonesia, Depok, West Java; ${ }^{2}$ Department of Maternity Nursing, Faculty of \\ Nursing, Universitas Indonesia, Depok, West Java, Indonesia
}

\begin{abstract}
Background: Breast cancer is one of the major cancer types found among Indonesian women. This cancer diagnosis and its treatment causes perpetual financial burden for the women and their family. This study aims to identify the correlation between socio-demographics with financial toxicity among women with breast cancer in Indonesia.

Design and methods: This study design was cross-sectional with 109 respondents of Indonesian breast cancer survivors who were recruited using consecutive sampling. Quantitative data were collected with a demographic and a Comprehensive Score for Financial Toxicity (COST) questionnaires, then analyzed using Chi-Square test and linear regression method.

Results: The majority of the women were 18 to 55-years-old (75.2\%), married $(91.7 \%)$, employed $(80.7 \%)$, and having moderate income $(58.7 \%)$. Logistic regression analysis indicates that survivor's family as a primary wage earner $(\mathrm{p}=0.042)$, low-high income $(\mathrm{p}=0.043)$, and dependents number $(\mathrm{p}=0.012)$ are significantly associated with financial toxicity.

Conclusions: The financial toxicity among women with breast cancer was mainly correlated with the number of survivor's dependent and the household income. This study encourage related parties to establish socio-economic safety net for women with breast cancer, including their families.
\end{abstract}

\section{Introduction}

Cancer is an illness that requires high medical costs in its care and treatment. The type of cancer that mostly affects women in Indonesia is breast cancer at $42.1 \%$ per 100,000 population based on data from the Ministry of Health of Indonesia. ${ }^{1}$ Indonesia is a middle-income country with an emerging economy where most people are aspiring middle-class, accounting for almost half of the total population. ${ }^{2}$ A cancer diagnosis is, therefore, a financial concern for women in Indonesia.

Financial problems and cost concerns are common among cancer patients. Patients need to adjust their expenses with the income. However, they faced a high expenditure for cancer care and treatment, thus it is difficult to have a stable financial condition. In the United States, cancer is the second most expensive disease after heart disease, accounting for annual expenses of US\$ 124 billion in 2010, and increasing to US\$ 157 billion in 2020 . The $27 \%$ increase came from the cost of consulting and cancer therapy. ${ }^{3}$ In China, expenditure per patient with breast cancer is US\$8532 (8234-8831), while the average annual household income was US\$8607. ${ }^{4}$ In Indonesia, the government, through BPJS Kesehatan, the Indonesian governing body for Universal Health Coverage, reported cancer accounted for approximately US\$183 million from the body's cost coverage in $2018 . .^{5}$ The increase in cost creates problems for not only the patients and their families but also doctors, health service facilities, health service providers, and insurance agency or government financing agencies. $^{3}$

Despite the healthcare coverage for cancer in Indonesia, an amount of expense is still spent by the cancer patient's household for healthcare and treatment. Out-of-pocket (OOP) expenses such as transportation expenses, non-medical or treatment modalities uncovered by BPJS Kesehatan, and other expenses spent to adjust the lives of the patients with cancer in order to accommodate their treatment regime puts a burden on their household. The ACTION Study Group studied that 12 months after a cancer diagnosis, $48 \%$ of patients with cancer in ASEAN experienced financial catastrophe. ${ }^{6}$

The financial adverse effects induced by cancer and its treatment is termed as financial toxicity. Another definition is that financial toxicity in patients with cancer is the subjective financial distress and objective financial burden caused by cancer treatment and its related costs. ${ }^{7}$ It is a familiar term in the discussion of cancer treatment and drug costs.

Financial toxicity (FT) in patients with cancer is a growing problem. It is known to be linked with worse mortality. The correlation is theorized to be caused by worse general well-being, decreased quality of life because of lifestyle changes caused by a lack of living costs, and non-optimal cancer treatment. ${ }^{8}$ A pilot study found that with the high out-of-pocket expenses of cancer, patients are forced to spend less on their living costs such as food, clothing, leisure activities/ spending, and to work longer hours to

Significance for public health

Understanding the socio-demographic characteristics correlated with financial toxicity of breast cancer survivors are important in designing future policy and health interventions which may enhance the survivorship adjustment of breast cancer patients and quality of life. It also expected to define the best approach for preventing financial toxicity which is sensitive to particular social, financial, and cultural disparities of Indonesian breast cancer survivors. 
balance them. ${ }^{9}$ Furthermore, it is reported that patients with financial toxicity were more likely to be noncompliant with medication, doctor's visits, and medical tests. Patients with financial toxicity were also more likely to be less caring for their mental health. ${ }^{10}$ Financial toxicity was also found to cause a higher risk-taking attitude in patients with cancer in Indonesia. ${ }^{11}$

Previous studies have identified several factors to have a varying degree of influence in financial toxicity experienced by patients. Factors of the socio-demographic nature, such as level of income, education level, race, and employment, have positively affected financial toxicity in patients with cancer. ${ }^{12}$ While some themes were consistent in financial toxicity research, varying results in which factor contributes more to worse financial distress were reported. ${ }^{13-15}$

Despite the high number of researches done on breast cancer in Indonesia, a specific study for financial toxicity experienced by breast cancer patients in Indonesia numbered low compared to the high prevalence of cancer. There is a gap in knowledge of what affects financial toxicity in cancer patients in Indonesia, particularly in the population of breast cancer patients. This study is thus aimed to identify the correlation of socio-demographic factors with financial toxicity for women with breast cancer in Indonesia. Understanding these factors are important in designing future policy and health intervention which help to increase the breast cancer survivorship and quality of life. It also expected to define best approach in preventing financial toxicity in conjunction with particular social, financial, and cultural disparities of Indonesian breast cancer survivors.

\section{Design and methods}

This research used a quantitative approach with a cross-sectional research design. The research design was chosen to determine the factors that can affect financial toxicity in women with breast cancer. The data collection was conducted for two months, from early May to the end of July 2020, at a Public Hospital in Central Jakarta, where the sampling was carried out in the Tumor Surgery Polyclinic unit and the Oncology Section of its Obstetrics and Gynecology unit. The sampling used in this study was consecutive, and direct sampling was carried out by researchers to respondents. The inclusion criteria were: 1) women with breast cancer aged 18 years and older; 2) being hospitalized and or were undergoing treatment for breast cancer; 3 ) have undergone surgery, chemotherapy, radiation, or a combination of the three as treatment. The exclusion criteria were patients with recurring cancer cases and agreed to participate in this study. A total of 125 women were assessed for eligibility in this hospital, but 16 were excluded (10 respondents had recurrent cancer, 5 women refused to participate, and 1 respondent did not complete the questionnaire).

The data collection tool used is a questionnaire consisting of a demographic questionnaire and the Comprehensive Score for Financial Toxicity (COST) questionnaire. The socio-demographic questionnaire consisted of 13 socio-demographic items. The items were age, marital status, education level, employment, income, number of doctor visits, wage earner, cancer stage, type of treatment, clinician's communication, indirect expenses, and number of dependents. The COST questionnaire was a questionnaire developed by de Souza, et al. (2014) to measure financial toxicity in cancer patients. ${ }^{16}$ The instrument has been tested for reliability and validity and has shown excellent internal consistency. The Cronbach $\alpha$ was $0.92 .{ }^{17}$ The questionnaire was translated into Indonesian Language and was put through a pilot test to 54 respon- dents to measure the translated questionnaire's reliability and validity. The translated questionnaire showed internal consistency with a Cronbach $\alpha$ value of 0.895 .

The Comprehensive Score for Financial Toxicity (COST) questionnaire is a widely used questionnaire in measuring Financial Toxicity. It consists of 11 statements related to patients' financial situation during a specific time frame mentioned in the questionnaire. Each statement was indexed from 1 to 5 , with 1 as "completely disagree" and 5 as "completely agree". The average of obtained values was calculated to get an index value representing respondents' financial toxicity. The closer the average index value to 5 , the more severe the financial toxicity is.

Data analysis was performed on the data collected from the fully completed questionnaires. The researchers performed descriptive statistics (mean, median, SD, frequency, percentage, minimum, and maximum) to analyze the demographic characteristics. Bivariate and multivariate analyses, namely the Chi-Square test and linear regression method, were performed to identify the relationships between the variables. We used SPSS software version 22 (SPSS Inc., Chicago, IL, USA) to assist our statistical works.

This research has received ethical approval with the number: SK-116/UN2.F12.DI.2.1/ETIK/2020 from the Research Ethics Committee of the Faculty of Nursing, University of Indonesia. Prior to data collection, every individual approached as a participant was informed of the basic information of the study. Those who agreed to participate in the study were required to fulfill an informed consent to participate in the study. The identity of the respondents was kept confidential with the use of numeric coding to the questionnaires. The respondents were asked to complete the questionnaire by themselves. The researchers prepared assistance to complete their questionnaire should there were illiterate respondents. However, all participants were literate.

\section{Results}

Of 109 respondents. Most of the women are within the productive age range $(75,2 \%)$ and are married. The majority finished high school or higher education $(86,2 \%)$ and worked as a housewife. More than half comes from middle-income households with their spouses or other family members as the wage earner. Table 1 shows the distribution of each socio-demographic variables.

Financial toxicity was measured with the Comprehensive Score for Financial Toxicity (COST) questionnaire. The Financial Toxicity Index median was 3.55 in which indicated that the average respondents were close to the more severe financial toxicity (Table 2).

The socio-demographic characteristics and financial toxicity were further analyzed with the bivariate test to determine the correlation between the two variables. According to the p-value, selected items were then analyzed further with linear regression modeling. The result of the analysis is presented in Table 3. The factors analyzed with linear regression are the items that in the bivariate analysis have a $p$-value $<0.25$, while those with a $p$-value $>0.25$ will be excluded from modeling. However, if these factors are substantially important, they can be considered as candidates for multivariate analysis. According to the bivariate analysis, 10 out of 12 socio-demographic factors were included in multivariate analysis, including: marital status, education, employment, income, number of hospital visit, wage earner, cancer stage, type of treatment, indirect expenses, and number of dependents.

The results of the multivariate analysis showed that there were 
eight stages of modeling. The eighth stage is the final modeling, and it is obtained that the p-value in the modeling meets the modeling criteria. Thus, the dominant socio demographic factors that affect financial toxicity in patients with breast cancer are indirect expense $(p=0.012)$, wage earner $(p=0.042)$, and income $(p=0.043)$ (Table 4). Linear regression of index financial toxicity is $3.833+0.355$ wage earner +0.175 income -0.432 indirect expenses $\left(R^{2}=14 \%\right)$.

\section{Discussion}

This study aimed to examine the correlation between sociodemographic characteristics and financial toxicity in women with breast cancer in Indonesia. This study finds that the majority of respondents have worse financial toxicity (Table 2). Effendy argued it is no surprise that many cancer patients reported unmet financial-related need, given the large portion (3/4) of the Indonesian population was under-insured. ${ }^{18}$ Since 2014 , the Indonesian government set up the Indonesian national health insurance through the Social Security Administering Body (Badan Penyelengara Jaminan Sosial, BPJS) Health Program, which covers cancer therapies. ${ }^{19}$ While this scheme offers comprehensive benefits for cancer treatment, despite the exception of some drugs (e.g., bevacizumab and cetuximab), cancer patients are still heavily burdened. Even in the Southeast Asian countries with established universal health coverage such as Malaysia, the patients are still heavily burdened with Out-of-Pocket (OOP) costs. ${ }^{20}$

Data analysis in the present study shows that socio-demographic factors, namely, the wage earner, the income, and the indirect expenses, are correlated with financial toxicity in this study's respondents. Lower income are at greater risk of being affected with worse financial toxicity, while patients as wage earners experience high financial burdens as a result of cancer care and treatment. This occurs due to reduced physical ability resulting from cancer treatment, which interferes with their ability to work, resulting in less income for both patients and families. The negative economic impact on survivors can be exacerbated by reduced income during care and or recovery and health services related to longterm care, as investigated in the research conducted by Mady et $a l{ }^{21}$ The correlation of low income on financial toxicity is also supported by Jing et al. and Hoang et al. that found low-income households have worse financial toxicity compared to those with high income. ${ }^{14,15}$ This is an expected phenomenon as higherincome provide them with more resources and, therefore, more resilience to cancer diagnosis's financial impact in general.

Respondents with high financial toxicity are seven times more likely to delay or avoid treatment due to financial constraints, especially if they are wage earners. The cancer experience caused a decrease in physical function and ability, leading to patients quitting their job. ${ }^{22}$ Pearce et al. similarly found that the wage earner's role has a significant, influential factor in financial toxicity because of the decreased financial ability as a result of quitting their job. This can also lead to non-compliance in cancer care and treatment. ${ }^{23}$

The COVID-19 Pandemic exacerbates the situation. As early as May 2020, 2.1 Million people in Indonesia become unemployed due to the pandemic's economic impact on most industries driving the country's economy. ${ }^{24}$ Many businesses are forced to lay off their workers or reduce their work time and, as a consequence, reduce their wages in order to cope with the loss in business related to the pandemic. The loss of income or prolonged unemployment due to the pandemic doubled patients' financial burden with can- cer. The pandemic has also impacted the delivery of cancer care in healthcare settings. Strict health protocols, physical distancing, and lockdowns are being implemented to contain the spread of COVID-19, thus delaying or disrupting care delivery for patients with cancer. ${ }^{25}$ The interruption could prove fatal to patients as it could lead to worsening conditions in patients. Especially in patients with more advanced breast cancer, it could lead to a costlier treatment option. More extensive treatment costs and the cost generated from the treatment's adverse effect are associated with

Table 1. Socio-demographic characteristics of respondents $(n=109)$.

\begin{tabular}{|c|c|c|}
\hline Factor & $\mathrm{n}$ & $\%$ \\
\hline $\begin{array}{l}\text { Age } \\
\begin{array}{l}18-55 \text { years } \\
>55 \text { years }\end{array}\end{array}$ & $\begin{array}{l}82 \\
27\end{array}$ & $\begin{array}{l}75.2 \\
24.8\end{array}$ \\
\hline $\begin{array}{l}\text { Marital status } \\
\text { Single } \\
\text { Married } \\
\text { Divorced }\end{array}$ & $\begin{array}{c}6 \\
100 \\
3\end{array}$ & $\begin{array}{c}5.5 \\
91.7 \\
2.8\end{array}$ \\
\hline $\begin{array}{l}\text { Education } \\
\text { Diploma/undergraduate } \\
\text { Highschool } \\
\text { Primary school }\end{array}$ & $\begin{array}{l}15 \\
69 \\
25\end{array}$ & $\begin{array}{l}13.8 \\
63.3 \\
22.9\end{array}$ \\
\hline $\begin{array}{l}\text { Employment } \\
\text { Employed } \\
\text { Unemployed } \\
\text { Housewife } \\
\end{array}$ & $\begin{array}{c}88 \\
5 \\
16\end{array}$ & $\begin{array}{c}80.7 \\
4.6 \\
14.7\end{array}$ \\
\hline $\begin{array}{l}\text { Income (IDR) } \\
\text { High }>4.3 \mathrm{mil} / \mathrm{month} \\
\text { Moderate } 2.9-4.3 \mathrm{mil} / \mathrm{month} \\
\text { Low }<2.9 \mathrm{mil} / \mathrm{month}\end{array}$ & $\begin{array}{l}29 \\
64 \\
16\end{array}$ & $\begin{array}{l}26.6 \\
58.7 \\
14.7\end{array}$ \\
\hline $\begin{array}{l}\text { Number of hospital visits } \\
\quad \leq 2 \\
\geq 3\end{array}$ & $\begin{array}{l}44 \\
65 \\
\end{array}$ & $\begin{array}{l}40.4 \\
59.6 \\
\end{array}$ \\
\hline $\begin{array}{l}\text { Wage earner } \\
\text { Myself } \\
\text { Husband/partner/other family members }\end{array}$ & $\begin{array}{l}17 \\
92\end{array}$ & $\begin{array}{l}15.6 \\
84.4\end{array}$ \\
\hline $\begin{array}{l}\text { Cancer stage } \\
\text { Stage } 0 \text { and } 1 \\
\text { Stage } 2 \text { and } 3 \\
\text { Stage } 4\end{array}$ & $\begin{array}{c}3 \\
105 \\
1\end{array}$ & $\begin{array}{c}2.8 \\
96.3 \\
9\end{array}$ \\
\hline $\begin{array}{l}\text { Type of treatment } \\
\text { Surgery } \\
\text { Chemotherapy/radiation } \\
\text { Combination }\end{array}$ & $\begin{array}{l}18 \\
14 \\
77\end{array}$ & $\begin{array}{l}16.5 \\
12.8 \\
70.6\end{array}$ \\
\hline $\begin{array}{l}\text { Clinicians' communication } \\
\text { Yes } \\
\text { No }\end{array}$ & $\begin{array}{l}29 \\
80\end{array}$ & $\begin{array}{l}26.6 \\
73.4 \\
\end{array}$ \\
\hline $\begin{array}{l}\text { Indirect expenses } \\
\text { Transportation } \\
\text { Transportation and lodging } \\
\text { Transportation, lodging, and children sick }\end{array}$ & $\begin{array}{c}2 \\
6 \\
\text { st } 101\end{array}$ & $\begin{array}{c}1.8 \\
5.5 \\
92.7\end{array}$ \\
\hline $\begin{array}{l}\text { Number of dependents } \\
\quad<2 \\
>2\end{array}$ & $\begin{array}{l}54 \\
55\end{array}$ & $\begin{array}{l}49.5 \\
50.5\end{array}$ \\
\hline
\end{tabular}

Table 2. Financial toxicity index $(n=109)$.

\begin{tabular}{lccc} 
Factor & Median & Minimum & Maximum \\
Index financial toxicity & 3.55 & 1 & 5 \\
\hline
\end{tabular}


Table 3. Bivariate analysis $(n=109)$.

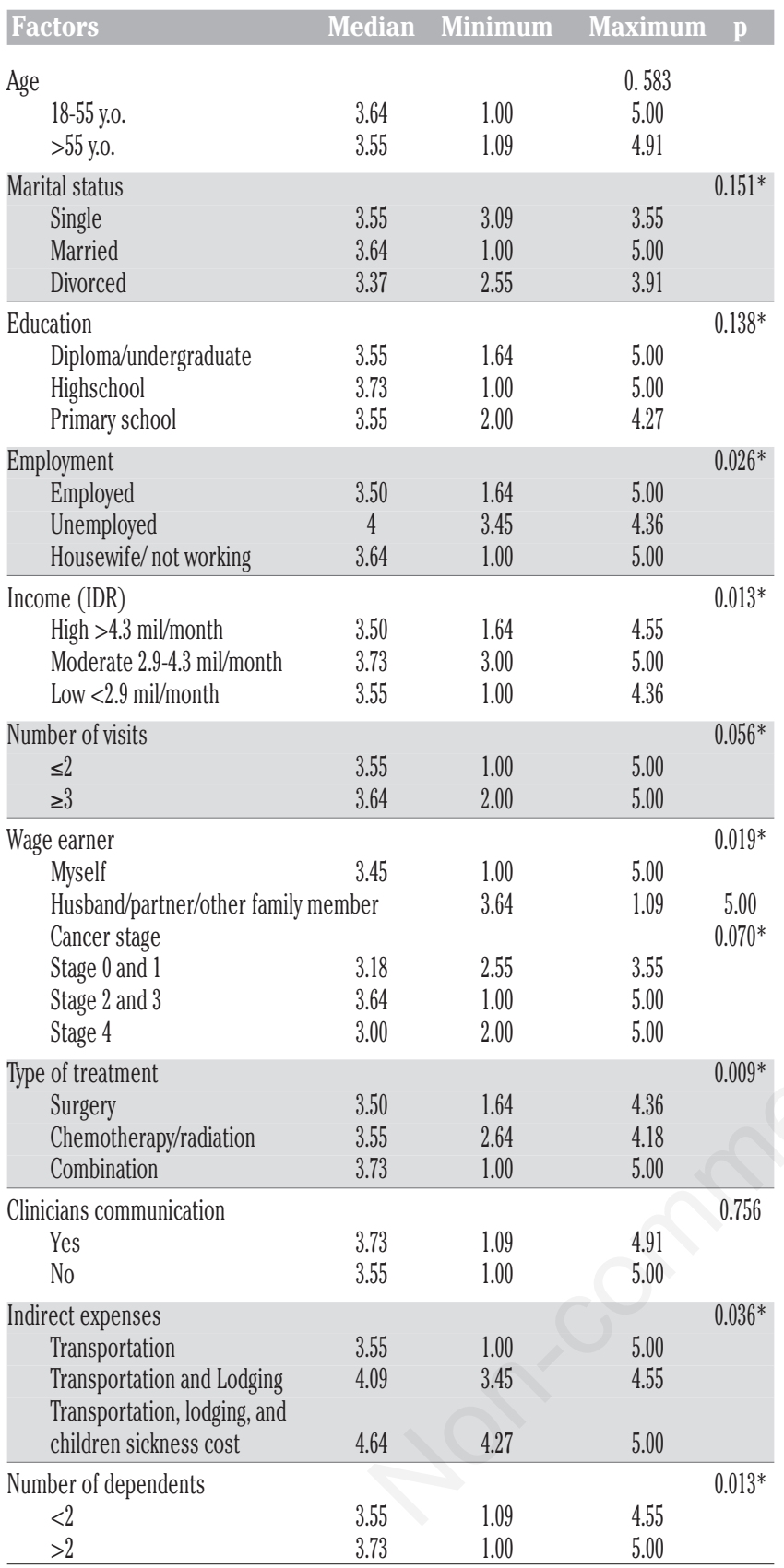

${ }^{*} \mathrm{p}<0.25$ (entered multivariate analysis). worse financial toxicity. ${ }^{14,26}$ In addition to the delay or disruption in treatment caused by the change in the healthcare system, the COVID-19 itself posed a great risk as patients with cancer are at a higher risk of being infected, leading to a higher mortality rate. ${ }^{27}$

This study also found indirect expenses affected financial toxicity experienced by patients with breast cancer. The cancer treatment involved other costs such as transportation, lodging, workrelated productivity losses, other than the medical expenditure. All participants in this study expressed some level of indirect expenditure, with $92.7 \%$ of them showed greater indirect expenditure spent on transportation, lodging, and the cost of sickness in children. A study of Expenditure and financial burden in China supported this study finding. It is showed that non-medical expenditure added a substantial amount of expenses. The treatment cost and non-medical expenditure combined presented $77.6 \%$ of households' unmanageable financial burden. ${ }^{4}$

The present study has limitations that should be noted and must be taken with caution. This study results cannot be generalized to other settings due to its single-center approach. Furthermore, our relatively small sample size limits the generalizability of the study. Further study on a larger scale should be conducted and involves other factors, such as quality of life, that could help understand the stress associated with the financial burden and the changes in patients' quality of life through cancer trajectory.

\section{Conclusions}

Most of the women with breast cancer in this study presented a high level of financial toxicity. Worse financial toxicity is associated with socio-demographic factors, namely wage earners, income, and indirect expenditure. This financial toxicity can negatively impact the well-being and quality of life of cancer patients. These study findings should encourage the government to provide a socio-economic safety net for women with breast cancer, including their families. The availability of comprehensive services between nurses, doctors, and the finance department is needed to help patients manage the objective financial burden and subjective financial difficulties. Furthermore, as financial toxicity is related to the quality of life of cancer patients, standardized tools to measure patients' financial distress are recommended to be used in patients' assessment. The assessment should provide data for the nurses to plan care and prepare to provide them with adequate information regarding financial support available for them.

Table 4. Linear regression multivariate analysis.

\begin{tabular}{|c|c|c|c|c|c|c|}
\hline \multirow[t]{2}{*}{ Stage modeling } & \multirow[t]{2}{*}{ Factor } & \multicolumn{2}{|c|}{ Unstandardized coefficient } & \multirow[t]{2}{*}{ Standardized coefficient } & \multirow[t]{2}{*}{$\mathrm{t}$} & \multirow[t]{2}{*}{ P } \\
\hline & & B & SE & & & \\
\hline \multirow[t]{4}{*}{ Final modeling } & Constant & 3.833 & 0.587 & & 6.534 & 0.001 \\
\hline & Wage earner & 0.355 & 0.173 & 0.197 & 2.054 & 0.042 \\
\hline & Income & 0.175 & 0.086 & 0.197 & 2.045 & 0.043 \\
\hline & Indirect expenses & -0.432 & 0.170 & -0.229 & -2.546 & 0.012 \\
\hline
\end{tabular}

Dependent variable: financial toxicity. 
Correspondence: Yati Afiyanti, Department of Maternity Nursing, Faculty of Nursing, Universitas Indonesia, Jalan Prof. Dr. Bahder Djohan, UI Depok Campus, West Java 16424, Indonesia. Tel. +62.21.78849120 - Fax: +62.21.7864124.

E-mail: yatikris@ui.ac.id

Key words: Breast cancer; financial toxicity; Indonesia; neoplasms; socio-demographic.

Contributions: MS, conceived and design the analysis; YA, manuscript drafting. All authors collected the data and performed the analysis. All authors contributed to the revisions of the publication draft and read and approved the final manuscript.

Conflict of interest: The authors declare no conflict of interest, financial or otherwise.

Acknowledgments: The authors would thank all respondents and all parties who had helped the completion of this research. High gratitude is delivered to Direktorat Riset dan Pengembangan Universitas Indonesia (No: NKB-4605/UN2.RST/HKP.05.00/2020) for providing research fund PUTI Saintekes 2020.

Ethics approval and consent to participate: The questionnaire and methodology for this study was approved by the Human Research Ethics Committee of the Nursing Faculty, Universitas Indonesia (Ethics approval no. SK-116/UN2.F12.DI.2.1/ETIK/2020).

Availability of data and materials: The data that support the findings of this study are available on request from the corresponding author. The data are not publicly available due to containing information that could compromise the privacy of research participants.

Conference presentation: This final manuscript has been presented at $7^{\text {th }}$ Virtual Biennial International Nursing Conference, Faculty of Nursing, Universitas Indonesia on September $24^{\text {th }}$, October $30^{\text {th }}$, November $16^{\text {th }} 2020$.

Received for publication: 31 January 2020

Accepted for publication: 7 May 2021

o Copyright: the Author(s), 2021

Licensee PAGEPress, Italy

Journal of Public Health Research 2021; 10(s1):2403

doi:10.4081/jphr.2021.2403

This work is licensed under a Creative Commons Attribution NonCommercial 4.0 License (CC BY-NC 4.0).

\section{References}

1. Ministry of Health of the Republic of Indonesia. [Hari Kanker Sedunia 2019 (World Cancer Day 2019)].[in Indonesian]. 2019. Available from: https://www.kemkes.go.id/article/view/ 19020100003/hari-kanker-sedunia-2019.html\#: :text= Hari\%20Kanker\% 20Sedunia\%2 0diperingati\%20setiap, I\%20Am\%20and\%20I\%20Will)

2. The World Bank. Aspiring Indonesia - expanding the middle class. Washington: World Bank; 2019.

3. Lentz R, Benson 3rd AB, Kircher S. Financial toxicity in cancer care: prevalence, causes, consequences, and reduction strategies. J Surg Oncol 2019;120:85-92.

4. Huang HY, Shi JF, Guo LW, et al. Expenditure and financial burden for common cancers in China: a hospital-based multicentre cross-sectional study. Lancet 2016;388:S10.

5. Kusuma AI, Nodia F. [Menkes: beban biaya BPJS akibat kanker capai Rp 2,7 Triliun (Minister of Health: BPJS costs due to cancer reach Rp. 2.7 trillion)].[in Indonesian]. suara.com [Internet]. 2019 Feb 4. Accessed: 2020 Oct 10 . Available

from:

https://www.suara.com/health/2019/02/04/155939/menkesbeban-biaya-bpjs-akibat-kanker-capai-rp-27-triliun

6. Bhoo-Pathy N, Yip CH, Peters SAE, et al. Policy and priorities for national cancer control planning in low- and middleincome countries: lessons from the Association of Southeast Asian Nations (ASEAN) Costs in Oncology prospective cohort study. Eur J Cancer 2017;74:26-37.

7. Carrera PM, Kantarjian HM, Blinder VS. The financial burden and distress of patients with cancer: understanding and stepping-up action on the financial toxicity of cancer treatment. CA Cancer J Clin 2018;68:153-65.

8. Zafar SY. Financial toxicity of cancer care: it's time to intervene. J Natl Cancer Inst 2016;108:djv370.

9. Zafar SY, Peppercorn JM, Schrag D, al. The financial toxicity of cancer treatment: a pilot study assessing out-of-pocket expenses and the insured cancer patient's experience. Oncologist 2013;18:381-90.

10. Knight TG, Deal AM, Dusetzina SB, et al. Financial toxicity in adults with cancer: adverse outcomes and noncompliance. J Oncol Pract 2018;14:e665-73.

11. Pangestu S, Karnadi EB. Financial toxicity in Indonesian cancer patients \& survivors: how it affects risk attitude. Cogent Med 2018;5:1.

12. Tucker-Seeley RD, Yabroff KR. Minimizing the "financial toxicity" associated with cancer care: advancing the research agenda. J Natl Cancer Inst 2015;108:djv410.

13. Abbott DE, Voils CL, Fisher DA, et al. Socioeconomic disparities, financial toxicity, and opportunities for enhanced system efficiencies for patients with cancer. J Surg Oncol 2017;115:250-6

14. Jing J, Feng R, Zhang X, et al. Financial toxicity and its associated patient and cancer factors among women with breast cancer: a single-center analysis of low-middle income region in China. Breast Cancer Res Treat 2020;181:435-43.

15. Hoang VM, Pham CP, Vu QM, et al. Household financial burden and poverty impacts of cancer treatment in Vietnam. Biomed Res Int 2017;2017:9350147.

16. de Souza JA, Yap BJ, Hlubocky FJ, et al. The development of a financial toxicity patient-reported outcome in cancer: The COST measure. Cancer 2014;120:3245-53.

17. de Souza JA, Yap BJ, Wroblewski K, et al. Measuring financial toxicity as a clinically relevant patient-reported outcome: the validation of the COmprehensive Score for financial Toxicity (COST). Cancer 2017;123:476-84.

18. Effendy C, Vissers K, Osse BHP, et al. Comparison of problems and unmet needs of patients with advanced cancer in a European Country and an Asian Country. Pain Pract 2015;15:433-40.

19. Agustina R, Dartanto T, Sitompul R, et al. Universal health coverage in Indonesia: concept, progress, and challenges. Lancet 2019;393:75-102.

20. Tangcharoensathien V, Patcharanarumol W, Ir P, et al. Healthfinancing reforms in southeast Asia: challenges in achieving universal coverage. Lancet 2011;377:863-73.

21. Mady LJ, Lyu L, Owoc MS, et al. Understanding financial toxicity in head and neck cancer survivors. Oral Oncol 2019;95:187-93.

22. Bouberhan S, Shea M, Kennedy A, et al. Financial toxicity in gynecologic oncology. Gynecol Oncol 2019;154:8-12.

23. Pearce A, Tomalin B, Kaambwa B, et al. Financial toxicity is more than costs of care: the relationship between employment and financial toxicity in long-term cancer survivors. J Cancer 
Surviv 2019;13:10-20.

24. Ing LY, Vadila Y. Implementing Indonesia's COVID-19 stimulus. East Asia Forum 2020. Accessed: 2020 Oct 10. Available from: https://www.eastasiaforum.org/2020/06/17/implementing-indonesias-covid-19-stimulus/

25. Kong YC, Wong LP, $\mathrm{Ng} \mathrm{CW}$, et al. Understanding the financial needs following diagnosis of breast cancer in a setting with universal health coverage. Oncologist 2020;25:497-504.

26. Jagsi R, Ward KC, Abrahamse PH, et al. Unmet need for clinician engagement regarding financial toxicity after diagnosis of breast cancer. Cancer 2018;124:3668-76.

27. Baddour K, Kudrick LD, Neopaney A, et al. Potential impact of the COVID-19 pandemic on financial toxicity in cancer survivors. Head Neck 2020;42:1332-8. 